\title{
The Effect of the Trace Elements Concentrations on the Cancerous and Healthy Tissues in Radiotherapy
}

\author{
Turan Sahmaran ${ }^{*}$, Ayse Kaskas ${ }^{2}$ \\ ${ }^{1}$ Kırıkhan Vocational School, Hatay Mustafa Kemal University, Hatay, Turkey \\ ${ }^{2}$ Department of Physics, Faculty of Science, Ankara University, Ankara, Turkey \\ Email: *tsahmaran@gmail.com
}

How to cite this paper: Sahmaran, T. and Kaskas, A. (2020) The Effect of the Trace Elements Concentrations on the Cancerous and Healthy Tissues in Radiotherapy. International Journal of Medical Physics, Clinical Engineering and Radiation Oncology, 9, 110-124.

https://doi.org/10.4236/ijmpcero.2020.93011

Received: June 1, 2020

Accepted: June 25, 2020

Published: June 28, 2020

Copyright $\odot 2020$ by author(s) and Scientific Research Publishing Inc. This work is licensed under the Creative Commons Attribution International License (CC BY 4.0).

http://creativecommons.org/licenses/by/4.0/

\begin{abstract}
The study is aimed to investigate the effect of the trace element concentrations in healthy and cancerous prostate tissues on dose distributions in radiotherapy. In this work, the trace element compounds completely soluble in the water were used and their concentrations given in the literature were mixed homogeneously with pure water. This is the first time study in literature as far as we know. The percent depth dose (PDD) measurements were performed using Elekta Synergy Platform Linac device for 6 and 18 MV photon energies. We also obtained the PDDs results by choosing higher trace element concentrations than given in literature in cancerous prostate tissue to see the effect on radiotherapy. The experimental measurements were compared with the results obtained from the GATE simulation code. The $\mathrm{TPR}_{20 / 10}$ was calculated for $10 \times 10 \mathrm{~cm}^{2}$ field size at $6 / 18 \mathrm{MV}$ energies photons and compared with simulation results. The differences between simulation and measurement for $6 \mathrm{MV}$ and $18 \mathrm{MV}$ photons are $1.75 \%$ and $1.82 \%$ respectively. The experimental results and simulations were presented an uncertainty lower than $3 \%$. Simulated dose values are in good agreement with less than $2 \%$ differences with the experimental results. We see that the trace element concentrations of healthy and cancerous tissues did not affect the dose distribution at high-energy photons. This is expected and well known result. We believe that this in vitro study is important for proving the reliability of the dose given in radiotherapy treatment once again.
\end{abstract}

\section{Keywords}

Radiotherapy, Percent Depth Dose, Trace Elements, GATE, GEANT4 


\section{Introduction}

Cancer is considered as one of the most deadly diseases and the leading causes of death worldwide [1]. Cancer treatment is performed by various methods such as surgery, chemotherapy, brachytherapy and radiotherapy or the application of these methods together. Approximately $50 \%$ of all cancer patients undergo external radiotherapy (ER) using photons [2] [3] [4]. Linear accelerators used in external beam radiation therapy treatments enable patients to be irradiated at different dose rates. The main aim of radiotherapy is to give the highest dose to the tumor and to give the lowest dose to the healthy tissue around the tumor. It is important to confirm the accuracy of the dose given to the patient during treatment planning by using the dose distribution algorithms. The particle transport calculations in the presence of an internal or external source, and the energy stored in the tissue can be determined by Monte Carlo (MC) calculations. In many studies, MC simulation packages have been used for radiation dosimeter calculations; such as OMEGA [5], MCNP4C [6] [7], EGS [8] [9]. In this research, the experimental results were simulated with the open-source code called Geant4 Application for Emission Tomography (GATE) MC simulation based on the GEANT4 toolkit (http://www.opengatecollaboration.org/). Geant4 is a software toolkit for the simulation of the interaction of particles with matter, and its application areas include high-energy physics experiments, astrophysics and astroparticle physics, nuclear physics, space science, medical physics and medical imaging, radiation protection [10] [11]. GATE plays a key role in the simulation of the radiotherapy experiments, PET, SPECT studies and design of new medical imaging devices [12] [13]. Recent studies have emphasized the importance of trace elements in the investigation about the possible causes of cancer [14] [15] [16] [17]. Trace elements have a significant effect as a component of many enzymes in all biological systems [18]. Although trace elements constitute a minor part of living tissues, they are important for vital processes. Trace element levels were determined to have deficiency or excess concerning the normal values in some diseases including cancer [19] [20]. Trace elements have different concentrations in healthy and cancerous tissues due to biological changes induced by the disease. The concentrations of trace elements in healthy and cancerous tissues or fluids have been recently obtained by using many experimental techniques such as particle-induced X-ray emission (PIXE), X-ray fluorescence analysis (XRF) and its total reflection geometry method (TRXRF), atomic absorption spectrometry (AAS) and neutron activation analysis (NAA) [21] [22] [23] [24] [25].

The concentration of trace elements has a noticeable effect on dose distributions at brachytherapy treatment (an internal radiation) which is used the low energy photon sources [26] [27]. In brachytherapy, the dosimetric impact of trace elements has been studied for normal and cancerous tissues using low energy photon sources with Monte Carlo (MC) calculations [28]. The results showed that in the presence of trace elements, dose distributions varied depend- 
ing on the atomic number and fraction of the elements in tissue.

The effect of the tissue composition on dose distribution was also investigated by using electron beams in radiotherapy [29]. Ghorbani et al. [29] showed that differences in dose distribution were not significant in various soft tissues and tissue-equivalent materials. However, due to the differences in the composition of the materials, it has been proposed to be investigated the uncertainties in the calculations.

This study aimed to determine the effect of the trace elements concentrations on dose distribution in healthy and cancerous prostatic tissues in radiotherapy. The trace elements concentrations given in the literature were mixed homogeneously inside the water phantom. Here, we used the trace element compounds completely soluble in the water. The experiment was performed for 6 MV photon beams of the Elekta Synergy Platform Linear Accelerator. The percent depth-dose distributions (PDD) of the concentration of each element were measured, and the results were compared with the simulations using GATE/GEANT4 code.

\section{Materials and Methods}

\subsection{Percentage Depth Dose Measurements}

The experiments were performed by Elekta Synergy Platform Linear Accelerator in the University of Health Sciences, Dışkapı Yıldırım Beyazıt Training and Research Hospital, Department of Radiation Oncology. This linear accelerator delivers two different photon energies at $6 \mathrm{MV}$ and $18 \mathrm{MV}$, and five electron energies at $6 \mathrm{MeV}, 9 \mathrm{MeV}, 12 \mathrm{MeV}, 15 \mathrm{MeV}$, and $18 \mathrm{MeV}$. Firstly, the profile analysis (symmetry, flatness, penumbra, etc.) was performed using IBA Blue Phantom ${ }^{2}$ according to standard protocols. The technical specifications of IBA Blue Phantom $^{2}$ are given in Table 1. Measurements were carried out with an electrometer, CC13 and FC65P ion chambers (IBA Dosimetry, Nuremberg, Germany). Ion chambers were calibrated by Turkey Atomic Energy Agency Secondary Standard Dosimetry Laboratory (ISDL).

Table 1. Technical specifications of IBA Blue Phantom².

\begin{tabular}{cc} 
Wall material & PMMA $^{*}$ \\
Exterior water tank dimensions $(\mathrm{L} \times \mathrm{W} \times \mathrm{H})^{* *}$ & $675 \mathrm{~mm} \times 645 \mathrm{~mm} \times 560 \mathrm{~mm}$ \\
Scanning volume $(\mathrm{X} / \mathrm{Y} / \mathrm{Z})$ & $480 \mathrm{~mm} \times 480 \mathrm{~mm} \times 410 \mathrm{~mm}$ \\
Position resolution & $0.1 \mathrm{~mm}$ \\
Position accuracy & $\pm 0.1 \mathrm{~mm}$ \\
Scanning speed & $50 \mathrm{~mm} / \mathrm{s}$ \\
Approximate volume & $200 \mathrm{lt}$ \\
Wall thickness/material & $15 \mathrm{~mm} / \mathrm{acrylic}$ \\
Weight (empty) & $45 \mathrm{~kg}$ \\
\hline
\end{tabular}

${ }^{\star}$ PMMA: Polymethyl methacrylate, ${ }^{*} \mathrm{~L}$ : Length, W: Width, H: Height. 
Water tank made from PMMA similar to Blue Phantom ${ }^{2}$ was used for each measurement. The water phantom dimension was $30 \times 30 \times 22 \mathrm{~cm}^{3}$ with $5 \mathrm{~mm}$ thickness and 20 liters volume. The outer surface of the water phantom was marked up to $20 \mathrm{~cm}$ with $1 \mathrm{~cm}$ intervals. $200 \mathrm{MU}$ was delivered at $6 \mathrm{MV}$ photons. The source to surface distance was $100 \mathrm{~cm}$ and the irradiation field sizes were $10 \times 10 \mathrm{~cm}^{2}$ and $20 \times 20 \mathrm{~cm}^{2}$. FC65P ion chamber was placed in a solid water phantom (RW3, IBA; Schwarzenbruck, Germany). Then, the water tank was located at the top of the solid water phantoms. Pure water and all chemical elements used in the measurements were obtained from Ankara University Chemistry Department Central Warehouse.

Firstly, the tissue phantom ratio for depths of 20 and $10 \mathrm{~cm}\left(\mathrm{TPR}_{20 / 10}\right)$ was obtained for $10 \times 10 \mathrm{~cm}^{2}$ field size to validate the simulation for 6 and $18 \mathrm{MV}$ photon energies [30]. The beam quality is specified by $\mathrm{TPR}_{20 / 10}$ for medical linear accelerators in high energy photons. The $\mathrm{TPR}_{20 / 10}$ can be delivered from the following equation:

$$
\mathrm{TPR}_{20 / 10}=1.2661 \times \mathrm{PDD}_{20 / 10}-0.0595
$$

$\mathrm{PDD}_{20 / 10}$ is the ratio of percent depth dose at 20 and $10 \mathrm{~cm}$ for a field size of 10 $\times 10 \mathrm{~cm}^{2}$ with $100 \mathrm{~cm}$ SSD. Then, the simulated PDD for each trace element concentration were compared with the experimental results for $10 \times 10 \mathrm{~cm}^{2}$ and $20 \times 20 \mathrm{~cm}^{2}$ field sizes in $6 \mathrm{MV}$ photon energies. The experimental setup used in the study is shown in Figure 1.

The FC65P ion chamber and some of the elements used in this study and the experimental setup for water and iron are shown in Figure 2. After reviewing the literature on trace element concentrations, the trace elements having the highest concentration in cancerous prostate tissues were determined

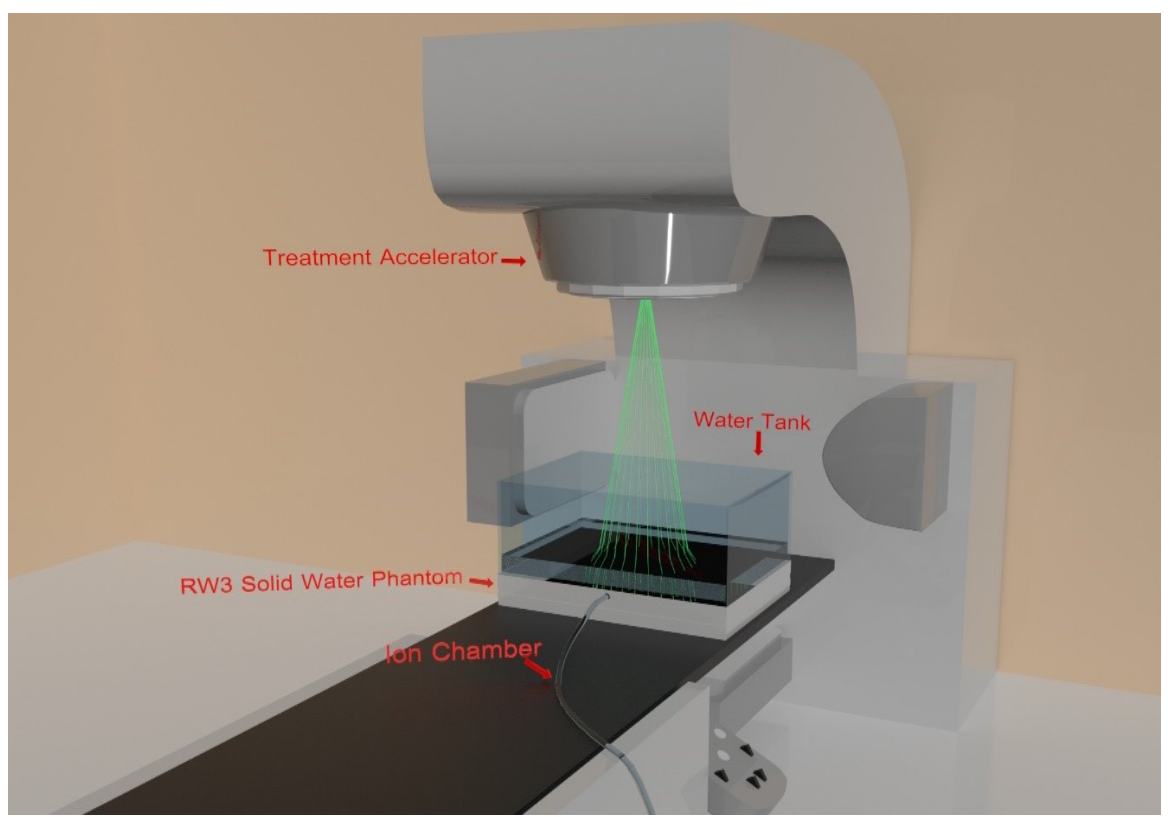

Figure 1. The schematic representation of linear accelerator and water tank. The components are not to scale. 


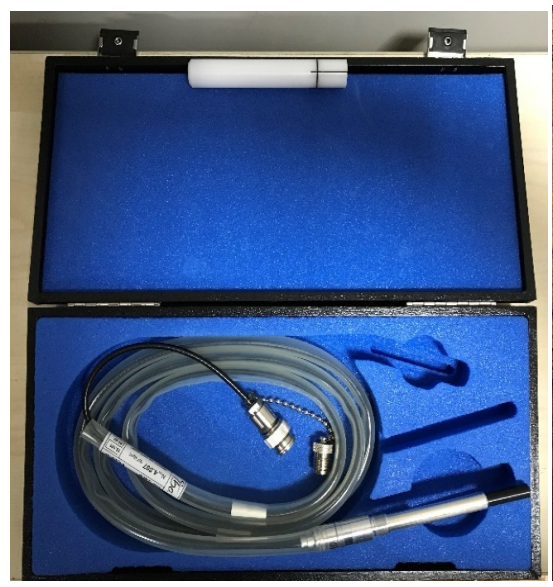

(a)

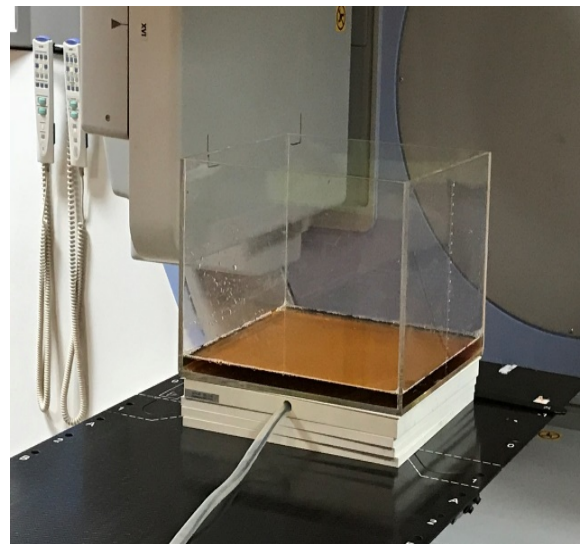

(c)

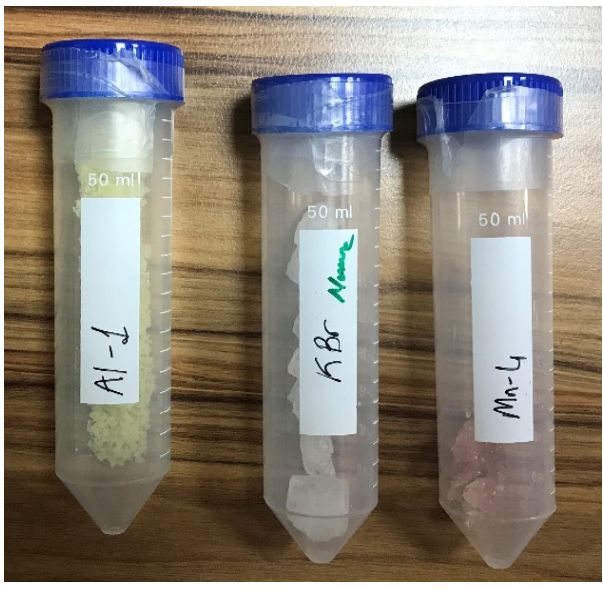

(b)

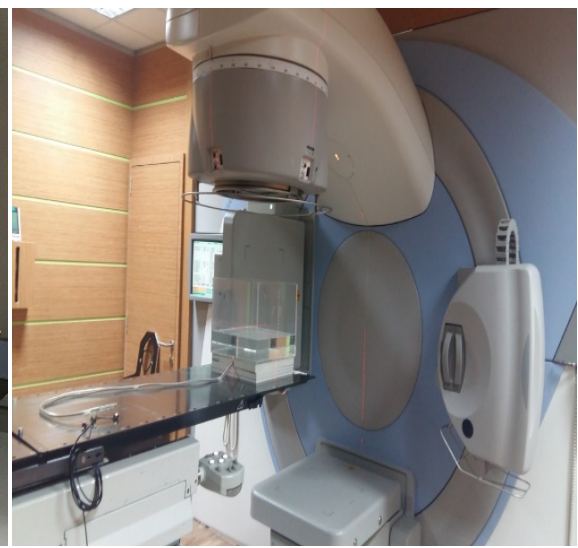

(d)

Figure 2. The FC65P ion chamber (a), some of the elements used in this study (b), experimental setup for iron $(\mathrm{c})$ and water $(\mathrm{d})$.

[23] [31] [32] [33] [34]. The PDD measurements were at first performed with pure water, which is a tissue-equivalent material. The concentrations for each trace element were calculated according to water phantom volume. Water-soluble compounds of these elements were given in Table 2 (https://periodic-table-of-elements.org/SOLUBILITY, Accessed: 10.05.2020). The trace element concentrations of healthy and cancerous prostate tissues given in the literature were used to obtain a mixture of water [35]. Then, the PDD measurements were carried out for each trace element compound.

\subsection{GATE Simulations}

For dosimetry related applications in radiation therapy, the GATE v8.1 release was used to simulate of Elekta Synergy Platform Linear Accelerator at $6 \mathrm{MV}$ photon energies. The water phantom material and size the same as the experiment was modelled in the simulation which is called a mainbox. The PDD curves were obtained for a $10 \times 10 \mathrm{~cm}^{2}$ and $20 \times 20 \mathrm{~cm}^{2}$ fields at $100 \mathrm{~cm}$ SSD by using dose of $20 \mathrm{~mm} \times 20 \mathrm{~mm} \times 10 \mathrm{~mm}$ and Dose Actor at these energies. The Dose Actor scores an energy deposited, distribution of dose and the associated 
Table 2. The trace element mass fraction ( $\mathrm{mg} / \mathrm{kg}$, dry mass basis) in the healthy and cancerous prostate tissues used in this study and their compounds which are completely soluble in water.

\begin{tabular}{ccccc}
\hline Elements & $\begin{array}{c}\text { Healthy Tissue* } \\
(\mathrm{mg} / \mathrm{kg})\end{array}$ & $\begin{array}{c}\text { Cancer Tissue* } \\
(\mathrm{mg} / \mathrm{kg})\end{array}$ & $\begin{array}{c}\text { Cancer Tissue } \\
\text { Rate } \times 4(\mathrm{mg} / \mathrm{kg})\end{array}$ & $\begin{array}{c}\text { Water-soluble } \\
\text { compound forms }\end{array}$ \\
\hline Aluminum & 34.2 & 328 & 1312 & $\mathrm{AlCl}_{3} \cdot 6 \mathrm{H}_{2} \mathrm{O}$ \\
Manganese & 1.34 & 7 & 28 & $\mathrm{MnCl}_{2} \cdot 4 \mathrm{H}_{2} \mathrm{O}$ \\
Bromine & 28 & 100 & 400 & $\mathrm{KBr}$ \\
Iron & 40 & 170 & 680 & $\mathrm{FeCl}_{3} \cdot 6 \mathrm{H}_{2} \mathrm{O}$ \\
Calcium & 160 & 1500 & 6000 & $\mathrm{CaCl}_{2} \cdot 2 \mathrm{H}_{2} \mathrm{O}$ \\
Potassium & 3934 & 1240 & 4960 & $\mathrm{KCl}^{2}$ \\
Zinc & 1061 & 127 & 508 & $\mathrm{ZnSO}_{4} \cdot 7 \mathrm{H}_{2} \mathrm{O}$ \\
Magnesium & 1071 & 355 & 1420 & $\mathrm{MgCl}_{2}$ \\
Sodium & 10987 & 7784 & 31136 & $\mathrm{NaCl}^{2}$ \\
\hline
\end{tabular}

${ }^{*}$ Zaichick and Zaichick [35].

statistical uncertainty in any volume [10]. We determined the Standard physics list with option 3 for photons, e- and e+ [36]. Four Kill Actors were defined at the surface of the phantom. The Cut in Region was set to $1 \mathrm{~mm}$ in the world and to $0.1 \mathrm{~mm}$ in the phantom for electrons, positrons and photons. The chemical compound of each trace element and their concentration in water were classified inside the Gate material list. The number of histories for all simulation was $3 \times$ $10^{9}$.

\section{Results and Discussion}

First, the flatness and symmetry of the instrument were determined by using the IBA Blue Phantom ${ }^{2}$ water phantom. In Linac, the flatness value should be less than $3 \%$ and the symmetry value should be less than $2 \%$. These values can be obtained in the largest field size at $100 \mathrm{~cm} \mathrm{SSD}$ and $10 \mathrm{~cm}$ depth [37]. $\mathrm{TPR}_{20 / 10}$ was calculated for $10 \times 10 \mathrm{~cm}^{2}$ field size at $6 / 18 \mathrm{MV}$ energies photons and compared with simulation results. The differences between simulation and measurement for $6 \mathrm{MV}$ and $18 \mathrm{MV}$ photons are $1.75 \%$ and $1.82 \%$ respectively, as shown by the values in Table 3. Data obtained with MC simulations presented less than $3 \%$ uncertainty. Similarly, data from all experimental measurements presented less than $3 \%$ uncertainty.

The difference between the experimental and simulation was calculated by

$$
\Delta d(r)=\left(\frac{\left(d_{e(r)}-d_{s(r)}\right)}{d_{e}^{\max }}\right) \times 100
$$

where $d_{e(r)}$ and $d_{s(r)}$ are doses at the position $r$ of the experimental and simulated curves and $d_{e}^{\max }$ is the maximum dose of the experimental curve. SPSS software (Version 22.0. SPSS. Inc., USA) was used to determine the statistical 
significance of the difference between experimental and simulation data by means of paired $t$ test. The $p$ value of less than 0.05 was considered statistically significant. Dose differences with p values are shown in Table 4.

Teixeira et al. [38] created the phase space of the Novalis Classic linear accelerator at $6 \mathrm{MV}$ energy performed the GATE simulation program and compared PDD and dose profiles with experimental data for $10 \times 10 \mathrm{~cm}^{2}$ and $3 \times 3 \mathrm{~cm}^{2}$ radiation field. They found that the $\mathrm{TPR}_{20 / 10}$ difference between simulation and measurement was about $1.5 \%$ for $6 \mathrm{MV}$. In our study, the difference between simulation and experiment was calculated at 1.75\%. In Figure 3 and Figure 4 the experimental measurements performed for pure water were compared with the simulated results at $6 / 18 \mathrm{MV}$ photons, at $10 \times 10 \mathrm{~cm}^{2}$ and $20 \times 20 \mathrm{~cm}^{2}$ field sizes. The PDD distributions for the concentrations of trace elements in healthy and cancerous prostate tissues were measured by using the trace element mass fraction as indicated in Table 2. The same conditions were defined and then simulated in GATE. ICRU 24 [39] recommends that the uncertainty in the dose given in radiotherapy should not exceed $\pm 5 \%$. In this study, the difference between measured and simulated results for the pure water measurement did not exceed $\pm 2 \%$.

Grevillot et al. [40] measured PDD and dose profiles at $6 \mathrm{MV}$ photons by using Elekta Precise Linac device and simulated with GATE program. They also found the dose differences between simulation and measurements approximately

Table 3. TPR, flatness and symmetry values for 6 and $18 \mathrm{MV}$ photons.

\begin{tabular}{ccccccc}
\hline \multirow{2}{*}{ Energy } & \multicolumn{2}{c}{$\mathrm{TPR}_{20 / 10}$} & \multicolumn{2}{c}{ Flatness } & \multicolumn{2}{c}{ Symmetry } \\
\cline { 2 - 6 } & Measurements & Simulation & Inline (\%) & Crossline (\%) & Inline (\%) & Crossline (\%) \\
\hline $6 \mathrm{MV}$ & 0.684 & 0.696 & 2.3 & 2.5 & 0.4 & 0.2 \\
$18 \mathrm{MV}$ & 0.774 & 0.795 & 2.6 & 2.4 & 0.5 & 0.3 \\
\hline
\end{tabular}

Table 4. Dose differences between pure water, CTCx4 and simulation.

\begin{tabular}{ccccc}
\hline & \multicolumn{2}{c}{ Average $\Delta d P D D$} & \multicolumn{2}{c}{ Average $\Delta d$ PDD } \\
\cline { 2 - 5 } & $10 \times 10 \mathrm{~cm}^{2}$ & p value & $20 \times 20 \mathrm{~cm}^{2}$ & p value \\
\hline Pure Water vs Simulation & $-0.55 \pm 1.05$ & 0.153 & $0.17 \pm 1.51$ & 0.614 \\
$\mathrm{AlCl}_{3} \cdot 6 \mathrm{H}_{2} \mathrm{O}(\mathrm{CTCx} 4)$ vs Simulation & $-0.22 \pm 1.17$ & 0.435 & $0.46 \pm 1.16$ & 0.760 \\
$\mathrm{MnCl}_{2} \cdot 4 \mathrm{H}_{2} \mathrm{O}(\mathrm{CTC} 4)$ vs Simulation & $-0.18 \pm 0.91$ & 0.408 & $0.38 \pm 1.21$ & 0.260 \\
$\mathrm{KBr}(\mathrm{CTCx} 4)$ vs Simulation & $-1.09 \pm 0.76$ & $<0.001$ & $-0.53 \pm 1.05$ & 0.017 \\
$\mathrm{FeCl}_{3} \cdot 6 \mathrm{H}_{2} \mathrm{O}(\mathrm{CTCx} 4)$ vs Simulation & $0.62 \pm 1.03$ & 0.015 & $1.01 \pm 1.02$ & $<0.001$ \\
$\mathrm{CaCl}_{2} \cdot 2 \mathrm{H}_{2} \mathrm{O}(\mathrm{CTCx} 4)$ vs Simulation & $1.23 \pm 1.47$ & 0.002 & $1.49 \pm 1.02$ & $<0.001$ \\
$\mathrm{KCl}(\mathrm{CTCx} 4)$ vs Simulation & $0.71 \pm 1.34$ & 0.102 & $-0.06 \pm 1.24$ & 0.716 \\
$\mathrm{ZnSO}_{4} \cdot 7 \mathrm{H}_{2} \mathrm{O}(\mathrm{CTC} 4)$ vs Simulation & $-0.52 \pm 1.55$ & 0.243 & $-0.39 \pm 1.46$ & 0.126 \\
$\mathrm{MgCl}_{2}(\mathrm{CTCx} 4)$ vs Simulation & $-1.14 \pm 1.51$ & 0.006 & $0.45 \pm 1.39$ & 0.206 \\
$\mathrm{NaCl}(\mathrm{CTCx} 4)$ vs Simulation & $1.21 \pm 1.03$ & $<0.001$ & $0.83 \pm 0.98$ & 0.007 \\
\hline
\end{tabular}



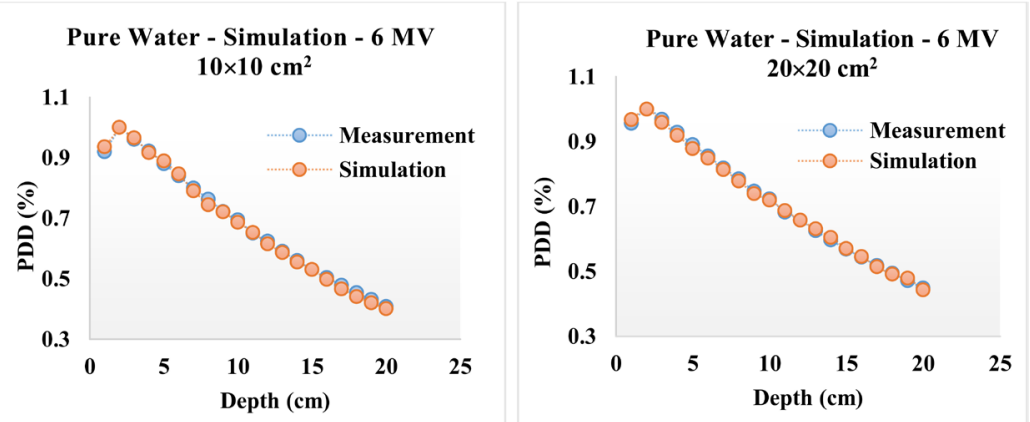

Figure 3. The comparison of experimental and simulated PDD's values for pure water at $10 \times 10 \mathrm{~cm}^{2}, 20 \times 20 \mathrm{~cm}^{2}$ field sizes for $6 \mathrm{MV}$ photons.
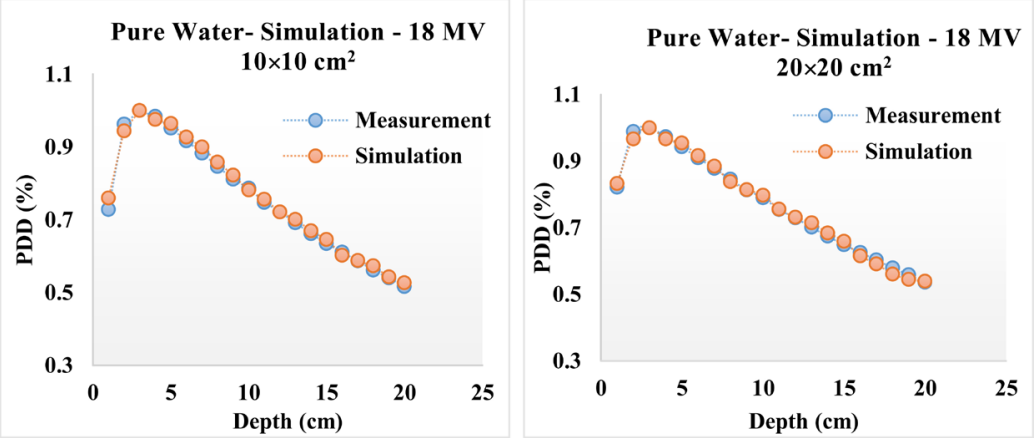

Figure 4. The comparison of experimental data and simulation results for pure water at $10 \times 10$ and $20 \times 20 \mathrm{~cm}^{2}$ field sizes for $18 \mathrm{MV}$ photons.

$1 \%-2 \%$. In similar studies, PDD and dose profiles measurements were performed for the various Linac devices and compared with different simulation codes. The results were consistent with each other [40] [41] [42] [43] [44]. The concentrations of the cancerous tissue (CTC) were increased the four times to investigate the effect of the maximum concentration on the dose distribution. In Figures 5-13, the simulated results of CTCx4 were compared with each experimental data set for healthy tissue (HTC) and cancerous prostate tissue concentrations. In the experimental results for each element concentration, there was no difference between the PDDs of the healthy tissue and cancerous tissue. Although the cancerous tissue concentration was increased by four times, it was found that the distributions were no different from the dose distributions obtained for cancerous, even healthy tissue concentrations. High energy photons primarily interact through Compton scattering, which is Z-independent. Therefore, the change in trace element concentrations in healthy and cancerous tissue did not affect the dose distribution. Since there were many experimental and simulated results, only the simulated data for CTCx 4 were given in figures.

Ghorbani et al. [29] studied the effect of the tissue composition on dose distribution for 8/12/14 MeV electron beams in radiotherapy. The various soft tissues and tissue-equivalent materials were simulated using MCNPX MC code for a Siemens Primus linear accelerator. There were no differences in dose distributions in various soft tissues and tissue-equivalent materials. Ghorbani et al. [45] 


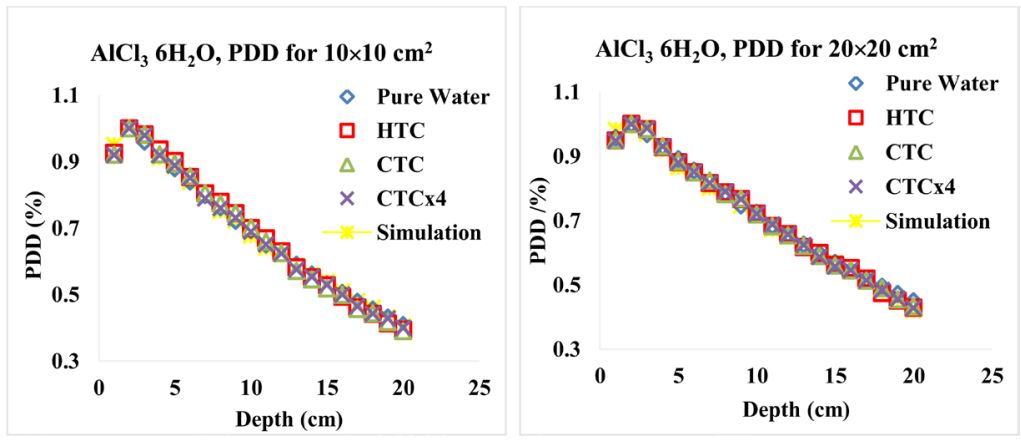

Figure 5. Comparison of experimental data and simulation results for pure water and $\mathrm{AlCl}_{3} \cdot 6 \mathrm{H}_{2} \mathrm{O}$ at $10 \times 10$ and $20 \times 20 \mathrm{~cm}^{2}$ field sizes for $6 \mathrm{MV}$ photons.
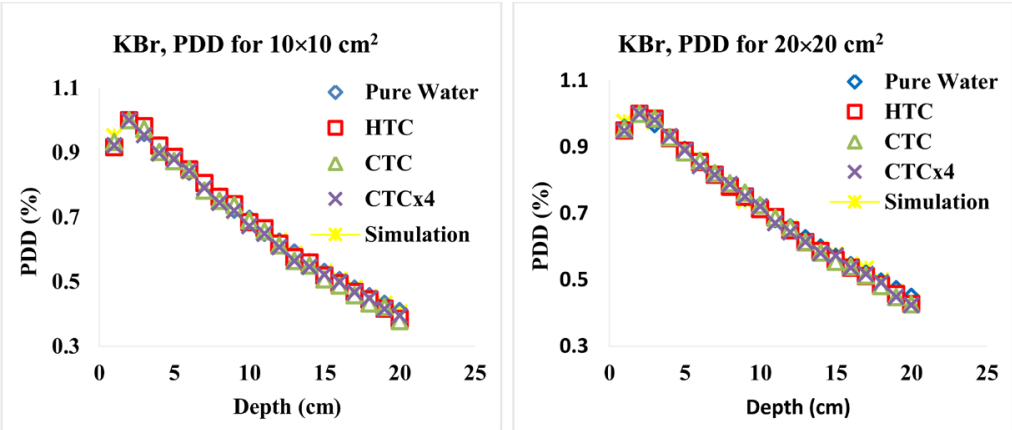

Figure 6. Comparison of experimental data and simulation results for pure water and $\mathrm{KBr}$ at $10 \times 10$ and $20 \times 20 \mathrm{~cm}^{2}$ field sizes for $6 \mathrm{MV}$ photons.
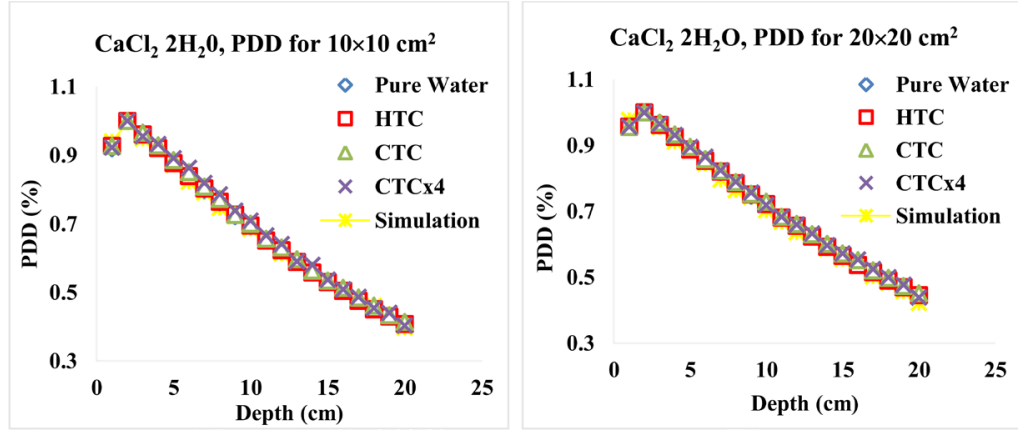

Figure 7. Comparison of experimental data and simulation results for pure water and $\mathrm{CaCl}_{2} \cdot 2 \mathrm{H}_{2} \mathrm{O}$ at $10 \times 10$ and $20 \times 20 \mathrm{~cm}^{2}$ field sizes for $6 \mathrm{MV}$ photons.
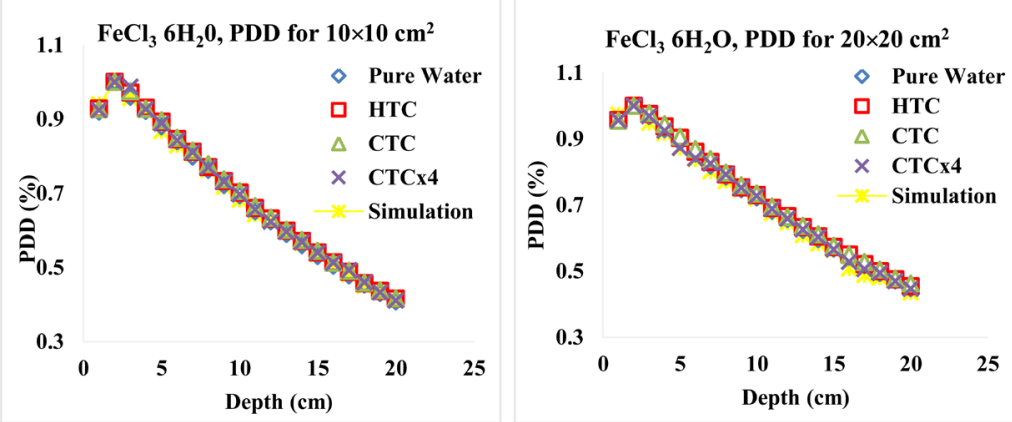

Figure 8. Comparison of experimental data and simulation results for pure water and $\mathrm{FeCl}_{3} \cdot 6 \mathrm{H}_{2} \mathrm{O}$ at $10 \times 10$ and $20 \times 20 \mathrm{~cm}^{2}$ field sizes for $6 \mathrm{MV}$ photons. 

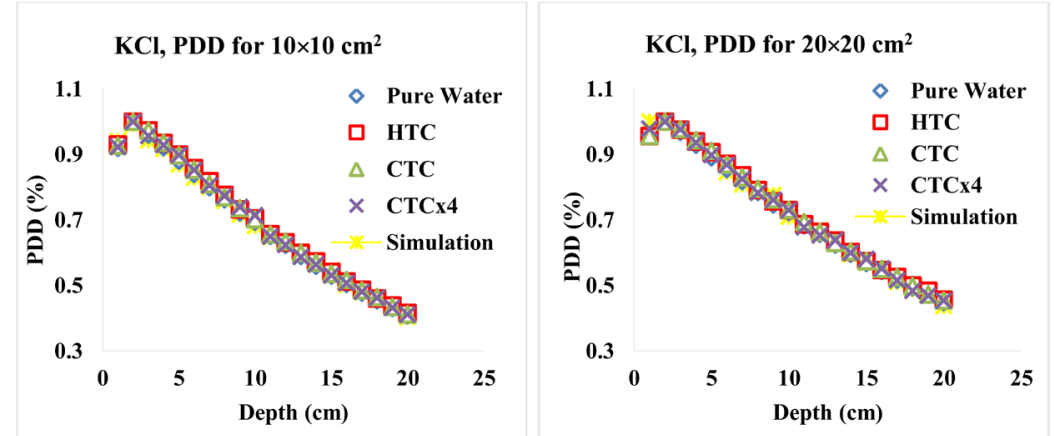

Figure 9. Comparison of experimental data and simulated results for pure water and $\mathrm{KCl}$ at $10 \times 10$ and $20 \times 20 \mathrm{~cm}^{2}$ field sizes for $6 \mathrm{MV}$ photons.
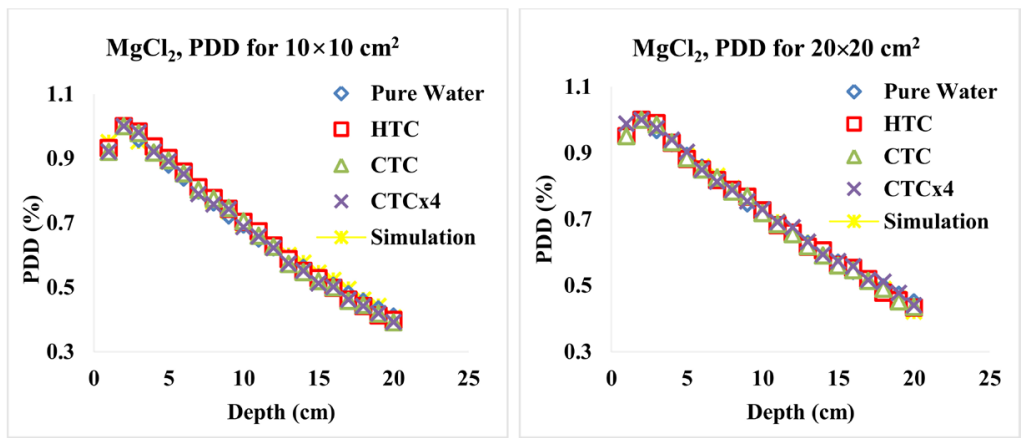

Figure 10. Comparison of experimental data and simulation results for pure water and $\mathrm{MgCl}_{2}$ at $10 \times 10$ and $20 \times 20 \mathrm{~cm}^{2}$ field sizes for $6 \mathrm{MV}$ photons.
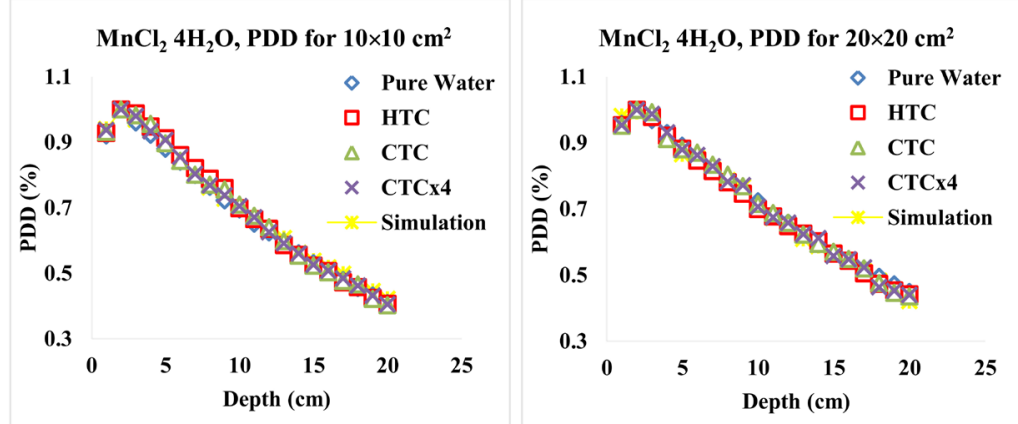

Figure 11. Comparison of experimental data and simulation results for pure water and $\mathrm{MnCl}_{2} \cdot 4 \mathrm{H}_{2} \mathrm{O}$ at $10 \times 10$ and $20 \times 20 \mathrm{~cm}^{2}$ field sizes for $6 \mathrm{MV}$ photons.

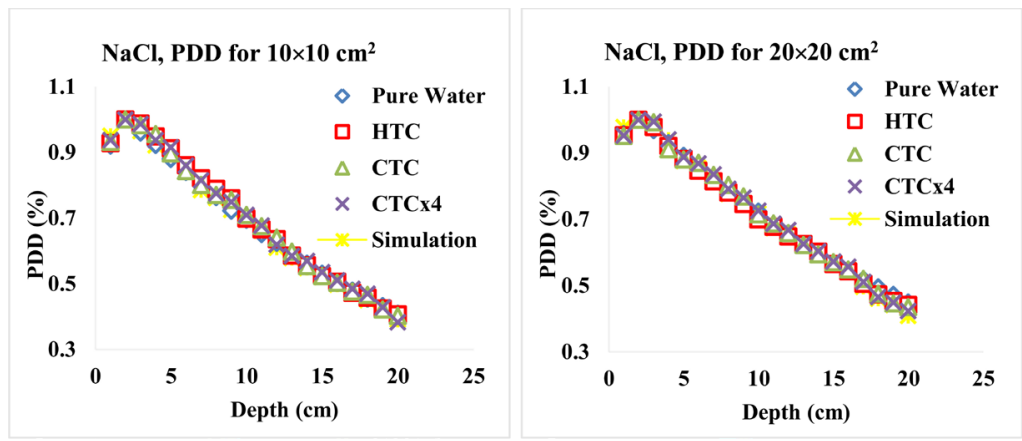

Figure 12. Comparison of experimental data and simulation results for pure water and $\mathrm{NaCl}$ at $10 \times 10$ and $20 \times 20 \mathrm{~cm}^{2}$ field sizes for $6 \mathrm{MV}$ photons. 

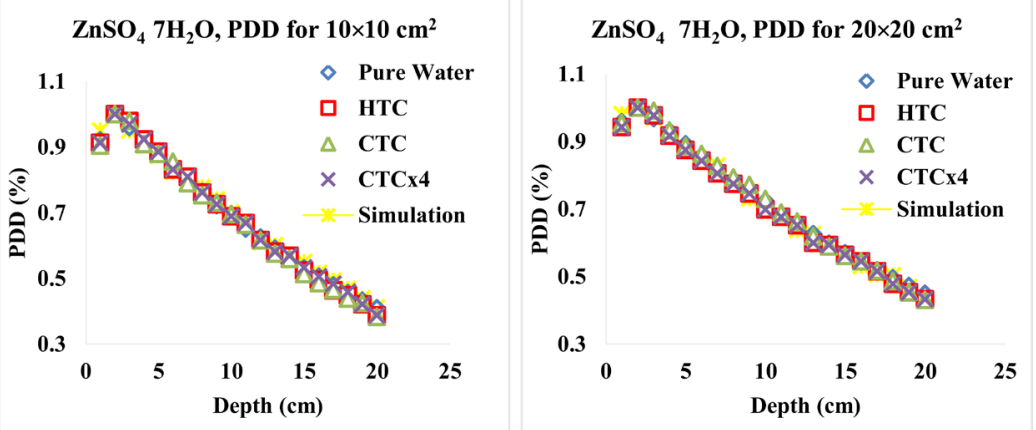

Figure 13. Comparison of experimental data and simulation results for pure water and $\mathrm{ZnSO}_{4} \cdot 7 \mathrm{H}_{2} \mathrm{O}$ at $10 \times 10$ and $20 \times 20 \mathrm{~cm}^{2}$ field sizes for $6 \mathrm{MV}$ photons.
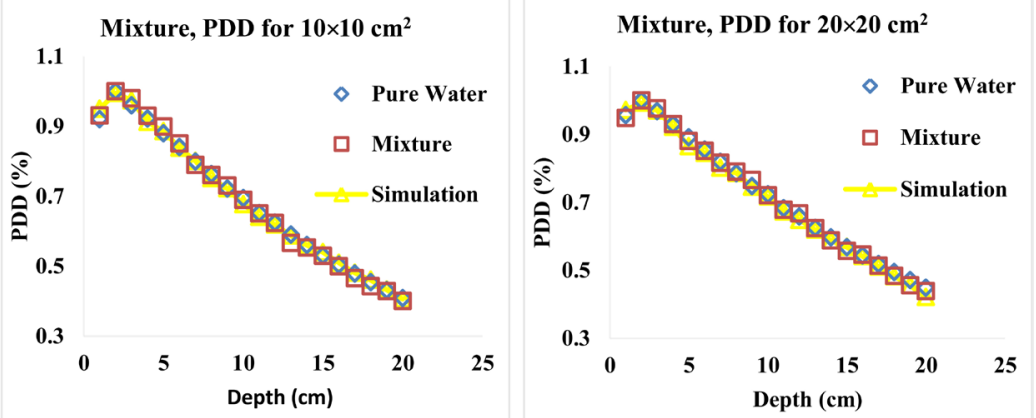

Figure 14. Comparison of the experimental data and simulation results, for pure water and mixture of nine elements at $10 \times 10$ and $20 \times 20 \mathrm{~cm}^{2}$ field sizes for $6 \mathrm{MV}$ photons.

also searched the effect of the soft-tissue composition on dose distribution using Siemens Primus linear accelerator at $6 \mathrm{MV}$ photons. The soft tissue and three types of tissue-equivalent materials were also simulated using MCNPX MC code for Siemens Primus linear accelerator. They found minor differences between dose distributions in various soft tissues and tissue-equivalent materials.

White et al. [28] determined the dose distribution for the trace element concentrations at healthy or cancerous human tissues with low energy photon sources in brachytherapy. They simulated the dose distribution with Geant 4 v9.3 and found that the different trace element concentration between healthy and cancerous prostate tissues affected the dose distribution and it should not be ignored.

In Figure 14, the experimental data performed with pure water and mixture of nine elements (CTCx4) for $6 \mathrm{MV}$ photons, at $10 \times 10 \mathrm{~cm}^{2}$ and $20 \times 20 \mathrm{~cm}^{2}$ field sizes were compared with the simulation.

\section{Conclusion}

To investigate the effect of trace element concentrations in tissue on dose distribution, the experimental and simulated PDD values for pure water, healthy and cancerous prostate tissues were obtained at $6 \mathrm{MV}$ photon energy. The experimental values of PDD were in a good agreement with the simulated data using GATE simulation code. There is a difference of less than $2 \%$ between the meas- 
ured and simulated results. The experimental results and simulations were presented an uncertainty lower than $3 \%$. As expected, it is seen that the difference between the trace element concentrations of healthy and cancerous tissues did not affect the dose distribution at high-energy photons. This is expected and well known result. We believe that this in vitro study is important for proving the reliability of the dose given in radiotherapy treatment once again.

\section{Conflicts of Interest}

The authors declare no conflicts of interest regarding the publication of this paper.

\section{References}

[1] Stewart, B.S. and Wild, C.P. (2014) World Cancer Report (WHO).

[2] Delaney, G., Jacob, S., Featherstone, C., et al. (2005) The Role of Radiotherapy in Cancer Treatment: Estimating Optimal Utilization from a Review of Evidence-Based Clinical Guidelines. Cancer, 104, 1129-1137. https://doi.org/10.1002/cncr.21324

[3] Mogarrio, A.M.F. (2016) Study of Trace Elements Concentration in Cancerous and Healthy Bladder, Colon and Lung Tissues. Master's Thesis, Dissertation for the Degree of Master of Science in Biomedical Engineering, Nova de Lisboa.

[4] Slotman, B.J., Cottier, B., Bentzen, S.M., et al. (2005) Overview of National Guidelines for Infrastructure and Staffing of Radiotherapy. Radiotherapy and Oncology, 75, 349-354. https://doi.org/10.1016/j.radonc.2004.12.005

[5] Komanduri, M.A. and Steve, B.J. (1998) Do We Need Monte Carlo Treatment Planning for LINAC Based Radiosurgery? A Case Study. Medical Dosimetry, 23, 161-167. https://doi.org/10.1016/S0958-3947(98)00012-0

[6] Mesbahi, A. (2007) Dosimetric Characteristics of Unflattened 6 MV Photon Beams of a Clinical Linear Accelerator: A Monte Carlo Study. Applied Radiation and Isotopes, 65, 1029-1036. https://doi.org/10.1016/j.apradiso.2007.04.023

[7] Mesbahi, A., Reilly, A.J. and Thwaites, D.I. (2006) Development and Commissioning of a Monte Carlo Photon Beam Model for Varian Clinical 2100EX Linear Accelerator. Applied Radiation and Isotopes, 64, 656-662. https://doi.org/10.1016/j.apradiso.2005.12.012

[8] Laub, W.U. and Nüsslin, F. (2003) Monte Carlo Dose Calculations in the Treatment of a Pelvis with Implant and Comparison with Pencil-Beam Calculations. Medical Dosimetry, 28, 229-233. https://doi.org/10.1016/j.meddos.2003.05.001

[9] Sanchez, M.L., Fernandez, M.P. and Fandino, J.M. (2019) An EGS Monte Carlo Model for Varian True BEAM Treatment Units: Commissioning and Experimental Validation of Source Parameters. Physica Medica, 64, 81-88. https://doi.org/10.1016/j.ejmp.2019.06.017

[10] Jan, S., Benoit, D. and Becheva, E. (2011) GATE V6: A Major Enhancement of the GATE Simulation Platform Enabling Modelling of CT and Radiotherapy. Physics in Medicine \& Biology, 56, 881-901. https://doi.org/10.1088/0031-9155/56/4/001

[11] Pia, M.G. (2003) The Geant4 Toolkit: Simulation Capabilities and Application Results. Nuclear Physics B, 125, 60-68. https://doi.org/10.1016/S0920-5632(03)90967-4

[12] Didi, S., Zerfaoui, M., Tayalati, Y., et al. (2015) Monte Carlo Simulation of 6 MV Elekta Synergy Platform Linac Photon Beam Using Gate/Geant4. Journal of Medical Physics, 40, 136-143. https://doi.org/10.4103/0971-6203.165077 
[13] Santin, G., Strul, D., Lazaro, D., et al. (2003) GATE, a Geant4-Based Simulation Platform for PET and SPECT Integrating Movement and Time Management. IEEE Transactions on Nuclear Science, 50, 1516-1521. https://doi.org/10.1109/TNS.2003.817974

[14] Carvalho, M.L., Magalhaes, T., Becker, M., et al. (2007) Trace Elements in Human Cancerous and Healthy Tissues: A Comparative Study by EDXRF, TXRF, Synchrotron Radiation and PIXE. Spectrochimica Acta, 62, 1004-1011. https://doi.org/10.1016/j.sab.2007.03.030

[15] Costello, L.C. and Franklin, R.B. (1998) Novel Role of Zinc in the Regulation of Prostate Citrate Metabolism and Its Implications in Prostate Cancer. Prostate, 35, 285-296.

https://doi.org/10.1002/(SICI)1097-0045(19980601)35:4<285::AID-PROS8>3.0.CO; 2-F

[16] Milde, D., Altmannova, K. and Vyslouzil, K. (2005) Trace Element Levels in Blood Serum and Colon Tissue in Colorectal Cancer. Chemical Papers, 59, 157-160.

[17] Mclaughlin, J.K. and Schumann, L.M. (1983) Epidemiology of Renal Cell Carcinoma. In: Lilienfeldt, A., Ed., Reviews in Cancer Epidemiology, Alan R. Liss Inc., New York, 170-209.

[18] Margarita, G., Skalnaya, A. and Skalny, V. (2018) Essential Trace Elements in Human Health: A Physician's View. Publishing House of Tomsk State University, Tomsk, 612-615.

[19] Fukuda, H., Ebara, M., Yamada, H., et al. (2004) Trace Elements and Cancer. JMAJ, 47, 391-395.

[20] Schwartz, M.K. (1975) Role of Trace Elements in Cancer. Cancer Research, 35, 3481-3487.

[21] Huanga, Y.L., Sheua, J.Y. and Lina, T.H. (1999) Association between Oxidative Stress and Changes of Trace Elements in Patients with Breast Cancer. Clinical Biochemistry, 32, 131-136. https://doi.org/10.1016/S0009-9120(98)00096-4

[22] Kubala-Kukus, A., Braziewicz, J. and Banas, D. (1999) Trace Element Load in Cancer and Normal Lung Tissue. Nuclear Instruments and Methods in Physics Research $B, 150,193-199$. https://doi.org/10.1016/S0168-583X(98)01057-X

[23] Silva, M.P., Soave, D.F., Silva, A.R., et al. (2012) Trace Elements as Tumor Biomarkers and Prognostic Factors in Breast Cancer: A Study through Energy Dispersive X-Ray Fluorescence. BMC Research Notes, 5, Article No. 194. https://doi.org/10.1186/1756-0500-5-194

[24] Zaichick, V. and Zaichick, S. (2013) The Effect of Age on $\mathrm{Br}, \mathrm{Ca}, \mathrm{Cl}, \mathrm{K}, \mathrm{Mg}, \mathrm{Mn}$ and $\mathrm{Na}$ Mass Fraction in Pediatric and Young Adult Prostate Glands Investigated by Neutron Activation Analysis. Applied Radiation and Isotopes, 82, 145-151. https://doi.org/10.1016/j.apradiso.2013.07.035

[25] Zaichick, V. and Zaichick, S. (2016) Trace Element Contents in Adenocarcinoma of the Human Prostate Gland Investigated by Neutron Activation Analysis. Cancer Research and Oncology, 1, 1.

[26] Ghorbani, M., Salahshour, F., Haghparast, A., et al. (2014) Effect of Tissue Composition on Dose Distribution in Brachytherapy with Various Photon Emitting Sources. Journal of Contemporary Brachytherapy, 6, 54-67. https://doi.org/10.5114/jcb.2014.42024

[27] Landry, G., Reniers, B., Murrer, L., et al. (2010) Sensitivity of Low Energy Brachytherapy Monte Carlo Dose Calculations to Uncertainties in Human Tissue Composition. Medical Physics, 37, 5188-5198. https://doi.org/10.1118/1.3477161 
[28] White, S.A., Landry, G., van Gils, F., et al. (2012) Influence of Trace Elements in Human Tissue in Low-Energy Photon Brachytherapy Dosimetry. Physics in Medicine \& Biology, 57, 3585-3596. https://doi.org/10.1088/0031-9155/57/11/3585

[29] Ghorbani, M., Tabatabaei, Z.S., Vejdani, N.A., et al. (2015) Effect of Tissue Composition on Dose Distribution in Electron Beam Radiotherapy. Journal of Biomedicine, $5,15-24$

[30] International Atomic Energy Agency (IAEA) (2000) Absorbed Dose Determination in External Beam Radiotherapy: An International Code of Practice for Dosimetry Based on Standards of Absorbed Dose to Water. Vienna International Atomic Energy Agency.

[31] Leitao, R.G., Palumbo, A. and Souza, P.A.V.R. (2014) Elemental Concentration Analysis in Prostate Tissues Using Total Reflection X-Ray Fluorescence. Radiation Physics and Chemistry, 95, 62-64. https://doi.org/10.1016/j.radphyschem.2012.12.044

[32] Singh, B.P., Dwivedi, S., Dhakad, U., et al. (2016) Status and Interrelationship of Zinc, Copper, Iron, Calcium and Selenium in Prostate Cancer. Indian Journal of Clinical Biochemistry, 31, 50-56. https://doi.org/10.1007/s12291-015-0497-x

[33] Zaichick, V. and Zaichick, S. (2016) Trace Element Contents in Adenocarcinoma of Human Prostate Investigated by Energy Dispersive X-Ray Fluorescent Analysis. Journal of Adenocarcinoma, 1, 1. https://doi.org/10.21767/2572-309X.100001

[34] Zaichick, V. and Zaichick, S. (2017) Comparison of Chemical Element Contents in Normal and Benign Hyperplastic Prostate. Asian Journal of Urology, 6, 275-289. https://doi.org/10.1016/j.ajur.2017.11.009

[35] Zaichick, V. and Zaichick, S. (2017) Trace Element Levels in Prostate Gland as Carcinoma's Markers. Journal of Cancer Therapy, 8, 131-145. https://doi.org/10.4236/jct.2017.82011

[36] Geant4 (2008) Physics Reference Manual for Geant4. 115-135.

[37] Podgorsak, E.B. (2005) Radiation Oncology Physics: A Handbook for Teachers and Students. IAEA, Vienna, 161-173.

[38] Teixeira, M.S., Batista, D.V.S., Braza, D., et al. (2019) Monte Carlo Simulation of Novalis Classic 6 MV Accelerator Using Phase Space Generation in GATE/Geant4 Code. Progress in Nuclear Energy, 110, 142-147. https://doi.org/10.1016/j.pnucene.2018.09.004

[39] International Commission on Radiation Units and Measurements (1976) Determination of Absorbed Dose in a Patient Irradiated by Beams of X or Gamma Rays in Radiotherapy Procedures. ICRU Report No. 24.

[40] Grevillot, L., Frisson, T., Maneval, D., et al. (2011) Simulation of a 6 MV Elekta Precise Linac Photon Beam Using GATE/GEANT4. Physics in Medicine \& Biology, 56, 903-918. https://doi.org/10.1088/0031-9155/56/4/002

[41] Dowlatabadi, H., Mowlavi, A. and Ghorbani, M. (2017) Monte Carlo Simulation of Siemens Primus plus Linac for 6 and 18 MV Photon Beams. Journal of Biomedical Physics and Engineering, 7, 333-346.

[42] Duran-Nava, O.E., Torres-Garcia, E.R., Oros-Pantoja, R., et al. (2019) Monte Carlo Simulation and Experimental Evaluation of Dose Distributions Produced by a $6 \mathrm{MV}$ Medical Linear Accelerator. Journal of Physics Conference Series, 1221, Article ID: 012079. https://doi.org/10.1088/1742-6596/1221/1/012079

[43] Sardari, D., Maleki, R. and Samavat, H. (2010) Measurement of Depth-Dose of Linear Accelerator and Simulation by Use of Geant4 Computer Code. Reports of Practical Oncology and Radiotherapy, 15, 64-68. 
https://doi.org/10.1016/j.rpor.2010.03.001

[44] Tartar, A. (2014) Monte Carlo Simulation Approaches to Dose Distributions for 6 MV Photon Beams in Clinical Linear Accelerator. Biocybernetics and Biomedical Engineering, 34, 90-100. https://doi.org/10.1016/j.bbe.2014.01.002

[45] Ghorbani, M., Noghreiyan, A.V., Tabatabaei, Z.S., et al. (2019) Tissue Composition Effect on Dose Distribution in Radiotherapy with a 6 MV Photon Beam of a Medical Linac. Journal of Cancer Research and Therapeutics, 15, 237-244.

https://doi.org/10.4103/jcrt.JCRT_706_16 